\title{
La retórica y el discurso administrativo
}

\author{
Rhetoric and administrative discourse \\ David Galicia Osuna* y María Esther Monroy Baldí
}

Universidad Nacional Autónoma de México, México

Recibido el 31 de julio de 2014; aceptado el 22 de junio de 2015

Disponible en Internet el 28 de abril de 2016

\begin{abstract}
Resumen
El objetivo de este trabajo es mostrar que el discurso administrativo, expuesto en sus textos fundamentales, se puede ubicar en el campo de la retórica, en particular cuando buscan persuadir y cuando hacen sus propuestas heurísticas (Lakatos, 1989; Laudan, 1986; Polanyi, 1958). La retórica la entiendo, con Perelman (1989) y Toulmin (2007), como teoría de la argumentación que busca persuadir o convencer, así como producir modelos o constructos viables. Lo anterior en el campo de las proposiciones performativas (Austin, 1955), no demostrativas empíricamente, recuperando la racionalidad práctica aristotélica. Muestro en el trabajo desde la retórica, la pasión persuasiva en textos administrativos como los de Harold Koontz respecto a cómo solucionar «la jungla semántica» o desorden semántico administrativo; y Reyes Ponce proponiendo aumentar un sexto elemento en el proceso administrativo, que es previsión; así como la pasión heurística en los modelos «normativos», no descriptivos, propuestos primero por Harold Koontz, en sus 5 funciones de la administración, segundo por Mary Parker Follet con sus 3 modelos de mando, en franca controversia con el modelo autoritario. Ambas pasiones permiten entender la construcción de la realidad social, en particular, organizacional.

Derechos Reservados (C) 2016 Universidad Nacional Autónoma de México, Facultad de Contaduría y Administración. Este es un artículo de acceso abierto distribuido bajo los términos de la Licencia Creative Commons CC BY-NC-ND 4.0.
\end{abstract}

Palabras clave: Discurso administrativo; Retórica; Pasión heurística; Pasión persuasiva

\begin{abstract}
\footnotetext{
* Autor para correspondencia.

Correo electrónico: davidgaliciao@gmail.com (D. Galicia Osuna).

La revisión por pares es responsabilidad de la Universidad Nacional Autónoma de México.
}

The goal that has this paper is to show that the administrative discourse, exposed in its basic texts, can be located in the field of rhetoric, particularly when seeking to persuade; and when they make their heuristic 
proposals (Lakatos, 1989; Laudan, 1986; Polanyi, 1958). I understand the rhetoric, with Perelman (1989) and Toulmin (2007) as an argumentation theory that seeks to persuade or convince so as to produce models or viable constructs. This in the field of performative propositions, not demonstrative empirically (Austin, 1955) recovering the Aristotelian practical rationality. Sampling in this work from rhetoric, persuasive passion in administrative texts such as Harold Koontz on how to solve "the semantic jungle" or administrative semantic disorder; and Reyes Ponce proposing to raise and include a sixth element in the administrative process, which is forecast; heuristics and passion in "normative" not descriptive, proposed first by Harold Koontz, in its five functions of management, second by Mary Parker Follett three models of command, in open dispute with the authoritarian model. Both passions allow the understanding of social reality construction, in particular organizational.

All Rights Reserved @ 2016 Universidad Nacional Autónoma de México, Facultad de Contaduría y Administración. This is an open access item distributed under the Creative Commons CC License BY-NC-ND 4.0 .

Keywords: Administrative discourse; Rhetoric; Heuristic passion; Persuasive passion

Hay dos estados ideales para nuestra existencia: el de la extrema simplicidad [...] y el de la extrema cultura, en la que, gracias a la organización que somos capaces de darnos, se obtiene el mismo resultado que antes, pero ahora con necesidades y energías infinitamente más complejas y poderosas.

HÖLDERIN

Con Durkheim, Weber y Schutz nos preguntamos: ¿cómo es posible que los significados subjetivos se vuelvan facticidades objetivas?

Peter Berger, La construcción social de la realidad

\section{Introducción}

Una línea de investigación más de la filosofía administrativa (Galicia Osuna, 2013) que enfatiza las investigaciones no demostrativas, no cuantitativas, ni cualitativas, es la visión del discurso administrativo desde la retórica, como teoría de la argumentación (Perelman y Olbrechts, 1989: $47)^{1}$, con características performativas que participan en la construcción de la realidad social (Giddens, 1993) intencional (Austin, Searle, Berger) ${ }^{2}$. El objetivo de este trabajo es mostrar que numerosos textos ${ }^{3}$ e investigaciones en administración parecen moverse en el campo de la retórica, alejados de las demostraciones empíricas (contexto de justificación positivista). Desde los textos introductorios ${ }^{4}$, como los de Harold Koonz, Stoner, Hampton, Chiavenato, Reyes Ponce, Isaac

\footnotetext{
${ }^{1}$ Chäim Perelman y Lucie Olbrechts, en el capítulo uno «Demostración y argumentación» de su libro Tratado de la argumentación. La nueva retórica, oponen demostración lógica y empírica a argumentación (Perelman y Olbrechts, 1989).

${ }^{2}$ Berger y Luckmann (2008) y su obra La construcción social de la realidad, pese a desarrollar la propuesta constructivista, no consideran el lenguaje, los actos del habla, la pragmática, para entender este hecho, de que la realidad social es un constructo humano. Indagan por la sociología del conocimiento. Por ello Searle (1997), en su obra La construcción de la realidad social, no lo menciona. Sin embargo, lo consideramos un autor básico.

${ }^{3}$ Con Chäim Perelman puedo decir que la retórica no se reduce a discursos orales: incluimos los discursos escritos cortos y largos, como un libro o un texto.

${ }^{4}$ Como se señala en el trabajo, se consideran autores introductorios al discurso administrativo. Pese a parecer autores menores, ellos tienen un gran impacto en el mundo de la vida académica de iniciación, donde me parece hay que ejercer una función formativa respecto a la visión de dichos autores y textos introductorios al pensamiento administrativo. Son textos
} 
Valdivia, como de los textos de Henry Fayol, Mary Parker Follet, Peter Drucker, Chester Bernard, Henry Mintzberg, William Deming ${ }^{5}$, Juran, Peter Senge, Michael Porter, entre otros.

En esto sigo a Aristóteles $(2005: 44)^{6}$, al entender la retórica como «ciencia» de la persuasión, o convencimiento ${ }^{7}$, pero también como heurística — creación de modelos ${ }^{8}$ y de hipótesis(Lakatos, 1975), mediante la argumentación racional (Perelman y Olbrechts, 1989). Me parece que, en buena medida, los textos administrativos son textos retóricos, más que demostrativos, y cumplen al menos con 2 funciones: persuasiva y heurística. Ello, desde luego, no devalúa las proposiciones administrativas; por el contrario, muestra la importancia de los otros usos del lenguaje (Czarniawska, 1997) ${ }^{9}$ en la producción de conocimiento, también administrativo. Cómo hacer cosas con palabras ${ }^{10}$ de Austin $(1955)^{11}$ (1955) y Searle (1997) nos lleva a volver la vista a la semiótica (más allá de la semántica, preocupada por la verdad) por la pragmática, atenta a la relación proposición acción ${ }^{12}$. Tanto los griegos como en la Edad Media cultivaron la retórica, dándole un significativa importancia. La modernidad la marginó, devaluándola,

formativos y utilizados en la formación básica de los futuros administradores. Desde luego, no soy el primero en retomar estos autores, como Harold Koontz y Reyes Ponce. Jorge Ríos Szalay (1997), investigador de la División de Investigación de la Facultad de Contaduría y Administración, UNAM (DIFCA), hace un trabajo retomando a Harold Koontz y a Reyes Ponce en particular, desde luego, considerando el importante impacto de estos y otros autores introductorios en el mundo académico.

${ }^{5}$ En su libro Out of the Crisis o Salir de la crisis, los 14 puntos y 7 enfermedades de la gerencia están hechos con proposiciones performativas (Austin), retóricos, el uso de la argumentación es interesante para proponer su modelo persuasivo y heurístico. Veamos 2 puntos: a) Crear constancia en la mejora de productos y servicios, con el objetivo de ser competitivo y mantenerse en el negocio, además de proporcionar puestos de trabajo, y b) Adoptar una nueva filosofía de cooperación en la cual todos se benefician, y ponerla en práctica enseñándola a los empleados, clientes y proveedores. Dos enfermedades: a) Falta de constancia en los propósitos, y b) Énfasis en las ganancias a corto plazo y los dividendos inmediatos.

6 Ver el capítulo segundo, «Definición de la retórica», del libro primero del El arte de la retórica de Aristóteles (2005).

7 Si bien tomo persuasión y convencimiento como sinónimos, Karl-Otto Apel señala una diferencia histórica: la persuasión solo alcanza la adhesión de una creencia como verdadera por alguno o algunos participantes de un auditorio, es subjetiva, mientras que el convencimiento argumentativo racional no estratégico (por la fuerza y violencia) es el logro performativo de la adhesión de un auditorio universal respecto de una creencias como verdadera, es objetiva. Este es el fin que se desea con la retórica y aun por la ciencia convencional, con sus diferentes mecanismos, convencer a un auditorio universal respecto de una creencia o modelo.

${ }^{8}$ Una diferencia importante: Polanyi, Lakatos y Laudan hablan de modelos descriptivos, y en el trabajo se habla de modelos prescriptivos, lo que debe ser, lo mejor, para objetivarse por prácticas sociales instrumentales o mediante consenso racional, argumentativo.

${ }^{9}$ Czarniawska nos presenta del lenguaje, del discurso, la narrativa como otro uso del lenguaje, para la constitución de creencias, de conocimiento y de acciones, señalando cómo se hacen cosas con palabras y siguiendo a Austin (1955) como realidad social.

10 Para una mejor comprensión de la pragmática es importante no perder de vista la teoría de los actos del habla.

11 El texto de John Austin (1955) Cómo hacer cosas con palabras y el texto de John Searle (1997) La construcción de la realidad social; en este, especialmente en su capítulo 3, «Lenguaje y realidad social», se habla de esos otros usos del lenguaje, los no constatativos, lo no demostrativos, que forman parte de la retórica.

12 Respecto a las palabras que permiten hacer cosas, de acuerdo con la tesis de Austin, resalto la argumentación y la visión normativa en este texto, como palabras y enunciados que permiten hacer cosas: como persuadir y crear modelos, vinculados con conocimiento y acción. Czarniawska (1997), Barthes (1977), Bruner (1998) y Van Dijk (2008), destacan el aspecto narrativo del lenguaje, que me parece una línea interesante del lenguaje, mostrando otra línea de cómo hacer uso del lenguaje. Estos autores, de igual forma, se pueden ubicar en una línea descriptiva, cercanos a investigaciones cualitativas, ubicándose en una propuesta distinta a la que presento. Destaco la parte argumentativa, así como una línea de investigación normativa. Argumentativa, como señala Ambrosio Velasco, en la tradición seguida por Polanyi, Thomas Kuhn, Steve Fuller, John Nelson, Philip Kitcher, Richard Rorty, entre otros. Normativa, siguiendo la tradición de Platón, Rousseau, Charles Taylor, Sheldon Wolin, Leo Strauss y Hannah Arendt. 
epistemológicamente. La retórica como medio de expresión, como estilística discursiva, que tiene como fin la persuasión o el convencimiento, por el tipo de enunciados que la componen, no demostrativos, no constatativos o verificativos de forma empírica, fue hecha a un lado del conocimiento científico moderno. Se llegó a creer que con ella no era posible producir conocimiento «verdadero», y menos justificar racionalmente proposiciones. Las proposiciones de la retórica no se podían justificar racionalmente, en particular mediante algún método algorítmico, de comprobación empírica.

En este trabajo presento los siguientes temas: antecedentes, donde señalo que los estudios de la retórica en general y de la investigación científica son un campo que se empieza a conocer, por lo que se requiere mostrar un poco lo que se ha hecho. Señalo la metodología y la perspectiva epistemológica dominante, la demostrativa, en particular de forma empírica, por contrastación de proposiciones con la realidad, señalando que la retórica no pertenece a esa visión positivista. ¿Dónde puedo ubicar este trabajo? Desde luego, dentro de la retórica de la investigación científica. Más allá de la metodología demostrativa o constatativa está la retórica de la investigación científica que se ocupa de la heurística, como contexto de descubrimiento, y la persuasión como contexto de justificación, contextos distintos a los de Hans Reichenbach. Paso a presentar la retórica de la investigación científica, mostrando a algunos autores importantes incorporados a ella. En los 2 últimos temas busco exponer de la retórica su pasión por la persuasión y su pasión por la heurística, en acción, en el discurso administrativo, básicamente en 3 autores: Koontz, Reyes Ponce y Mary Parker Follet. Pero aprovecho para mencionar los trabajos de 2 investigadores de la DIFCA ${ }^{13}$ y de otros autores importantes. Los procesos de argumentación, las controversias, las críticas, la discusión, las mostramos en el trabajo.

\section{Antecedentes}

Veamos algunas de las virtudes de la retórica. El logro de la adhesión o la adopción de ciertas creencias como verdaderas, propongo, con Gadamer, Heidegger, Popper, Kuhn, Habermas, Rorty, Laudan, que no se debe a un método científico, sino a un proceso de comunicación retórica, persuasiva o convencimiento, semejante a las otras creencias que tenemos del mundo de la vida. Nos alejamos de la idea de los contextos de Hans Reichenbach ${ }^{14}$ (Bárcenas, 2002), esto es, de que el conocimiento que tengo viene del contexto de descubrimiento, donde la realidad se nos da, nos ofrece el conocimiento, y mediante la observación, y por inducción, abstraemos los conceptos y las leyes. Jurgen Habermas (1997: 10) recuerda que este contexto sigue al mito de lo dado ${ }^{15} \mathrm{y}$ del pensamiento representador, y que la justificación racional se debe a la verificación (Hempel, 1950: 115-138) ${ }^{16}$ o falsación (Popper, 1980: 39) empírica, observacional y experimental. Propongo con los anteriores autores que el conocimiento que tenemos viene del pasado (círculo

\footnotetext{
13 La DIFCA es la División de Investigación de la Facultad de Contaduría y Administración, UNAM.

14 «La distinción entre "contexto de descubrimiento" y "contexto de justificación" fue trazada por H. Reichenbach para distinguir, entre otras cosas, la manera como realizan los descubrimientos en la ciencia y la manera como se justifican y aceptan», resaltando el contexto de justificación (Bárcenas, 2002).

15 Partiendo de cero, el conocimiento es dado al observador, de forma particular, mediante la observación, le es dado el concepto, la proposición que representa al objeto.

16 El concepto de verificación fue propuesto en particular por el positivismo lógico (Moritz Schlickn, Rudolf Carnap, Carl Hempel), concepto que se mostró como insuficiente por Popper (1980: cap. I, 27-46). Este pretendió «superarlo» con la propuesta de falsacionismo, propuesta que Lakatos cuestiona con su concepto de «programas de investigación científica», calificándolo de falsacionismo ingenuo.
} 
hermenéutico), no lo inventé. Siempre partimos, no de cero, sino de una pre-comprensión heredada, según Heidegger; siempre estamos en una comprensión (tradición, con sus prejuicios), de acuerdo con Gadamer; estamos en «el tercer mundo» de Popper (cultura); en algún paradigma, según Kuhn; o pertenecemos a alguna tradición de investigación, según Laudan. Todas ellas no son mi creación, no son producto de mi observación personal de la realidad, de mi inducción. Tampoco su verdad depende de una justificación racional metodológica demostrativa empírica, ya verificativa o por falsación. Los procesos de comunicación, la persuasión y el convencimiento, la retórica, participaron en la adhesión, la adopción, de dichas creencias como ciertas, y permiten entender tanto el contexto de descubrimiento de creencias como del proceso de justificación, por argumentación racional. Todo esto basado en la argumentación racional, elemento básico de la retórica de la investigación científica.

Antes que Toulmin ${ }^{17}$ y Perelman y Olbrechts (1989), con su Tratado de la argumentación, la nueva retórica, el campo de la retórica había sido estudiado no solo por los sofistas, sino con seriedad por Aristóteles, Tomás de Aquino, Kant y Nietzsche, abriendo un camino a los otros enunciados no demostrativos, no constatativos, no fácticos, pero fundamentales para comprender los fenómenos sociales (y naturales), así como para la construcción de la realidad social, en particular sus organizaciones.

Ahora podemos decir que, con la retórica, las proposiciones no solo permiten buscar la verdad, también permiten convencer, persuadir, forzar, constituir patrones de acción y modelar la realidad social. Este otro «conocimiento» ya había sido advertido por Peter Berger y Thomas Luckmann (2008) en su texto La construcción social de la realidad, pero en especial por John Searle (1997) en La construcción de la realidad social. La realidad social, y por ello organizacional, es una construcción humana, ahora desde la retórica, desde la pasión heurística y la pasión por la persuasión y el convencimiento, mediante proposiciones no demostrativas.

Tenemos ejemplos de textos retóricos, argumentativos, que buscan persuadirnos acerca de creencias metodológicas. La lectura de Karl Popper, de Imre Lakatos, de Tohmas Kuhn, de Larry Laudan, de Richard Rorty, son textos que buscan persuadirnos o convencernos de algo: de cómo demarcar el conocimiento; de cómo elegir programas de investigación; del progreso científico dentro de una tradición de investigación; de la irrelevancia de la búsqueda de la verdad. Pero también de creencias de fenómenos sociales: los escritos de Frederick Hayeck, de Milton Friedman, de Herbert Simon, de igual forma, buscan convencernos de ciertas creencias: del proceso evolutivo de la economía; de que el modelo económico liberal es superior al socialismo; del hombre administrativo sobre el hombre económico. Nicolás Maquiavelo, Thomas Hobbes, Juan Jacobo Rousseau, Alexis Tocqueville y John Rowls de igual forma hacen lo suyo en política; pese a jugar con enunciados descriptivos, consideran enunciados normativos, prescriptivos; pero con ambos enunciados, buscan convencernos de algo: de cómo conservar el poder en una monarquía, de un estado absolutista, de un modelo de democracia, de una idea de justicia (distributiva). Todos ellos objetos no fácticos, no empíricos, en un primer momento, pero con posibilidades de materializarse construyendo la realidad social.

De igual manera, numerosos textos de administración se mueven en el campo de la retórica, como decía Lakatos (1975: 71), desde el poder heurístico (Michael Polanyi, 1958) como desde la pasión persuasiva (Velasco, 2006: 269). Las controversias son importantes en administración

\footnotetext{
17 Con Toulmin se llegan a desarrollar varios modelos de argumentación. Ver capítulo 3, «La forma de los argumentos» (Toulmin, 2007: 129-192). Santibañez (2010) resume algunas de las figuras: a) proposición, prueba, confirmación y conclusión; b) tesis, razón, prueba de la razón, embellecimiento y conclusión, y c) argumento perfecto: proposición, prueba, confirmación de la prueba, ornato y resumen o conclusión.
} 
y el uso del recurso argumentativo fundamental para resolver dichas controversias. Jorge Ríos Szalay (1997) entra en un proceso de discusión respecto de los teóricos de la administración mexicanos respecto a los norteamericanos: «Mitos sobre el proceso administrativo: el modelo teórico-descriptivo vis-a-vis el modelo técnico-prescriptivo». En el desarrollo no vemos la aplicación de algún método experimental para resolver la discusión, o un proceso de verificación o falsación empírica, sino que se da una confrontación básicamente argumentativa. La intención es persuadir a un auditorio o comunidad científica de sus tesis. La interesante investigación de Luis A. Cruz Soto (2010) respecto al concepto de autoridad —en la que defiende su legitimidad desde el concepto de autoridad de Aristóteles, donde la legitimidad de la autoridad, de la dominación, requiere el reconocimiento racional, informado y voluntario de los dominados- es un trabajo argumentativo, no de demostración empírica. Koontz y Weihrich (1998: 21) escribe un libro con pasión persuasiva; igual buscando mostrar que tiene la verdad, la solución a «la jungla semántica», al caos administrativo, proponiendo a un auditorio que tiene el modelo ordenador de esa jungla: su modelo con 5 funciones: planeación, organización, integración, dirección y control, donde se puede ubicar cualquier concepto de administración, ordenándose. Adopta la metáfora de «la jungla de la teoría administrativa» (Koontz et al., 2012: 21-27), o la «selva de la teoría administrativa» ${ }^{18}$, para referir a las controversias, al «desorden» administrativo en que ha caído, que se dan en el discurso administrativo respecto a la diversidad de «teorías» y conceptos administrativos en pugna: Taylor (modelo científico), Henry Fayol (modelo clásico), Max Weber (modelo burocrático), Elton Mayo (modelo de factores sociales), o March, Peter Drucker (dirección de empresas), Herbert Simon (hombre administrativo), William Ouchi (teoría Z), Chester Bernard, Henry Mintzberg (los papeles administrativos), William Deming, Joseph Jurán y Crosby (elevación de la calidad), Michael Hammer (reingeniería), Senge (la quinta disciplina), McKinsey (las 7-S), Michael Porter (la estrategia corporativa). En la pugna se hace uso de metáforas (Morgan, 1991) que se enfrentan en las controversias, de cómo se debe entender una organización: como máquina, como organismo, como cerebro, como cultura, como sistema político. Frente a este caos semántico, Koontz trata de persuadirnos en un pesado libro de que tiene el «hilo de Ariadna» para no perderse en el laberinto semántico en el que ha caído el discurso administrativo. Volveremos a ello.

En este proceso retórico destacan 2 conceptos que Lakatos (1975), Laudan (1986) y Polanyi $(1958)^{19}$ habían resaltado de la retórica: la heurística y la persuasión (Velasco, 2000: 227). La primera, la heurística como generadora de hipótesis alejadas de un origen empírico —el conocimiento no viene de la realidad-, destacando la producción de modelos o constructos no empíricos pero viables. Y por otro lado, el proceso de persuasión, en 2 sentidos: el primero, que busca que una creencia, un modelo o constructo, misión, objetivo, meta, sea visto como «verdadero», adhesión, que le permite crear algún constructo, modelo; y un segundo momento, persuadir a tomar ciertas acciones, patrones de comportamiento, un modelo, ya por aceptación del mejor argumento, por consenso, por diálogo, por convencimiento o por racionalidad estratégica: la fuerza, la violencia, una orden, la amenaza, el poder, el argumentum ad baculum.

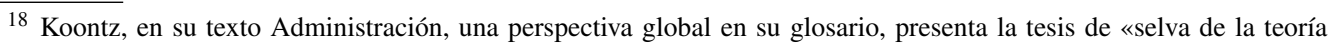
administrativa».

19 De Lakatos (1983: 65-119) hago referencia —de los programas de investigación científica compuestos de 3 elementos: núcleo firme y las dos heurísticas, la negativa y la positiva-, más que a su heurística negativa, a la positiva, que habla de la creación de problemas, de hipótesis, de modelos, de ampliar el campo de lo real: hace ver cosas nuevas. De Laudan hago referencia a la heurística no solo de hechos, sino conceptual: hace ver, crea, conceptos nuevos.
} 


\section{Más allá de la metodología demostrativa}

La modernidad tuvo grandes retóricos con alto grado de persuasión. Bacon y Descartes (Perelman y Olbrechts, 1989: 30) ${ }^{20}$, y después el Círculo de Viena, por ejemplo, lograron convencer de que el conocimiento se limita a aquellas creencias cuya verdad puede demostrarse o comprobarse racionalmente (Velasco, 2006), logrando que un auditorio considerable adoptara esa creencia. Esta creencia que alentaron impactó al auditorio de la modernidad. La idea básica afirmaba que un conocimiento era una creencia racional cuya verdad puede demostrase o comprobarse racionalmente. La justificación racional de la creencia consistía en el uso de algún método universal, seguro, único, algorítmico y concluyente, ya como demostración lógica o como comprobación empírica. Se señalaba o la demostración deductiva o la comprobación con base en la evidencia empírica, la manera de justificar racionalmente dicha proposición.

Esta racionalidad metódica deja fuera del conocimiento las creencias que no pudieran ser demostrables. Con este criterio, buena parte de las ciencias sociales, las humanidades, las deja como doxa, como meras opiniones plausibles, verosímiles, ya que pertenecen a un conocimiento práctico.

El conocimiento, entendido como conjunto de proposiciones demostrables por evidencias empíricas, dominó hasta el siglo pasado. Frege, Russel Carnap, Nuerath (Perelman y Olbrechts, 1989: 30 $)^{21}$ —en general el positivismo lógico— estaban convencidos de esta idea. Su retórica se enfocó a subrayar la verificación, la inducción, el contexto de descubrimiento, el contexto de justificación, la evidencia empírica, el método científico, la atención a la semántica y la sintaxis, desconociendo la pragmática, al giro pragmático, y criticando a la metafísica. Su capacidad de persuasión fue contundente. A esta hegemonía discursiva escaparon algunos. Heidegger fue uno de los que se alejó de las proposiciones con exigencia científica. Se suman Gadamer, Habermas; después, muchos más. Toulmin y Perelman rompieron definitivamente con este auditorio, y dedicaron sus esfuerzos a rehabilitar la retórica o la teoría de la argumentación. Perelman resume la idea dominante de la racionalidad: «En sentido amplio de la palabra, es racional aquello que está conforme a los métodos científicos y las obras de la lógica consagradas al estudio de los procedimientos de prueba». Bajo esta visión resulta extraño, en ciencia, hablar de Aristóteles, pero más de Cicerón, Quintiliano y Vico. Con Meyer (en Perelman y Olbrechts, 1989: 27-29) recordamos que «la retórica siempre resurge en periodos de crisis»; ahora crisis del conocimiento, políticas, económicas, sociales, morales, ambientales, éticas. En particular, en el discurso administrativo. Hay que hablar de lo mejor, de lo que debe ser, criticar, reflexionar, emitir juicios de valor. Seguir en esa línea positivista, como Perelman y Olbrechts, 1989: 30) señalan, sería una negligencia.

Más allá de esa racionalidad, con Perelman, la que ahora propongo, es la racionalidad adecuada al análisis y evaluación de proposiciones no demostrativas, a los argumentos, a las controversias sobre juicios de valor, en general a las ciencias sociales y humanidades y ahora a buena cantidad de proposiciones fundamentales de la administración. Nos ubicamos en la racionalidad práctica aristotélica, reivindicando las proposiciones de estas ciencias sociales y humanidades con validez cognoscitiva. Ver la retórica como teoría de la argumentación, con proposiciones no demostrables, pero con capacidad heurística como persuasiva. La retórica necesaria para entender qué pasa con

\footnotetext{
${ }^{20}$ Perelman nos habla de la tradición que se inició con Descartes de la concepción de la razón y del razonamiento, tradición que marcó el pensamiento occidental en los últimos siglos.

21 Perelman acusa un descuido de los lógicos: «La facultad de deliberar y de argumentar es un signo distintivo del ser racional, que los lógicos y teóricos del conocimiento han descuidado por completo, desde hace tres siglos, el estudio de los medios de prueba utilizados para obtener adhesión».
} 
la justicia, la democracia, los modelos de desarrollo, la bondad, el papel del Estado, del mercado; pero también con el proceso administrativo, las funciones de la administración, el hombre administrativo, la racionalidad económica, la racionalidad instrumental, la misión, las metas, las políticas, las normas, los perfiles de puesto, la centralización o descentralización del poder, la autoridad, el poder, modelos de comunicación (autoritarios o democráticos). La argumentación persuasiva y heurística que posibilita llegar a una «verdad» de cuál modelo administrativo es pertinente, de cómo mejorarlo; un modelo tayloriano, fordista, weberiano, toyotista, uno de relaciones humanas, un modelo de contingencias, un modelo sistémico, o quizá el modelo de Chiavenato de su TGA. Hay que voltear a ver los procesos racionales, no algorítmicos, no universales, procesos de argumentación desarrollados en las controversias y discusiones, en ciencias sociales y humanidades, pero ahora en administración.

\section{La retórica de la investigación científica}

La reivindicación de la retórica se veía venir con Hannah Arendt (2007: 205) ${ }^{22}$ en su defensa de la acción humana; con Isaiah Berlin (1958) ${ }^{23}$ y sus discusiones sobre las 2 libertades; con Sheldon Wolin (1996) con sus propuestas de teorías épicas, de la necesidad de buscar lo mejor haciendo juicios de valor. Pero en particular con la filosofía de la ciencia pospositivista, desde una perspectiva de pluralidad epistemológica, dejaron de ser jueces y describieron lo que pasa en la ciencia. Se dan cuenta de que en la investigación científica intervienen juicios de valor, prejuicios ontológicos, epistemológicos, conceptuales y metodológicos que se adoptan acríticamente, que forman parte de la tradición donde se han formado. Se dieron cuenta de que la aceptación o rechazo de hipótesis, de teorías, la evidencia o verificación empírica, así como el uso de alguna metodología, eran secundarios. Popper ya había señalado que no es posible refutar de manera concluyente alguna hipótesis. De igual forma, la justificación de teorías está más bien condicionada a convenciones y compromisos establecidos dentro de las comunidades científicas y sujetas a las controversias entre las distintas tradiciones (Laudan) o paradigmas (Kuhn) científicos. En esto están de acuerdo, además de Larry Laudan y Karl Popper, Michael Polanyi, Stephen Toulmin, Kuhn, Lakatos, Hesse, Feyerabend, Rorty Hacking y Fuller (Velasco, 2006). La argumentación retórica que se da en las controversias da sustento racional a los compromisos y convenciones que fundamentan las ciencias naturales, pero también sociales y en las humanidades. Ahora puedo decir que ello se da también en el discurso administrativo.

Una postura a la que me sumo es la denominada retórica de la investigación científica, con Polanyi, Kuhn, Fuller, Nelson, Kitcher. En esta, la investigación científica se entiende como un proceso dialógico que se desarrolla en comunidades científicas. En ella, el diálogo, la argumentación retórica desempeña un papel esencial para la defensa y el reconocimiento y justificación de hipótesis y teorías (fuerza persuasiva y contexto de justificación); así como para su crítica y sustitución por otras más razonables, formulando modelos, constructos alternativos (fuerza heurística y contexto de descubrimiento). La racionalidad es un proceso comunicativo entre personas de cierta comunidad que comparten presupuestos, debaten críticamente diversas tesis y buscan hacer

\footnotetext{
22 Su obra La condición humana es una muestra de la recuperación de los enunciados no demostrativos, de la retórica. Cualquier capítulo, pero en especial el quinto, «Acción», recupera la importancia del discurso, de la palabra, que nos inserta en el mundo (Arendt, 2007: 206).

${ }^{23}$ La interesante retórica de Berlin, sus discusiones y argumentación sobre las 2 libertades, nos lleva a la presentación de las otras proposiciones; se ve la pasión heurística en la creación de 2 modelos: la libertad negativa (Berlin, 1958: 3) y la libertad positiva (Berlin, 1958: 8), y la pasión persuasiva en la lectura de sus argumentos.
} 
consensos racionalmente en aspectos esenciales de la controversia. En administración, las controversias respecto al proceso administrativo son interesantes, donde se busca el convencimiento de un auditorio.

La racionalidad del juicio, del modelo, de la tesis, del constructo, emerge, por el consenso del diálogo, como fundamento revisable, válido, para ese consenso, en su contexto particular. Es una racionalidad contextual, que inclina por persuasión nuestra adhesión a ciertas opiniones, creencias, modelos, constructos, procesos, funciones, sin ser concluyente. Ello puede pertenecer y sustituir al contexto de justificación de H. Reichenbach.

Pero la retórica también tiene que ver con el contexto de descubrimiento, distinto al positivista. Ella no se limita a la persuasión de creencias, hipótesis, constructos, modelos; también, ella interviene en la construcción de metáforas, de modelos, de constructos que tienen una fuerza heurística, para el descubrimiento de hipótesis nuevas: cuando se habla de cuál es el proceso administrativo, se construye un modelo de proceso administrativo; cuando se define cómo es el hombre administrativo, se construye el modelo de hombre administrativo; cuando se piensa la administración burocrática, se construye el modelo de administración burocrática. Así, la retórica tiene que ver con 2 fuerzas: la heurística y la persuasiva. La heurística la ubicamos en el contexto de descubrimiento, y la persuasiva, en el contexto de justificación, ambos alejados de los contextos de descubrimiento positivista de Reinchebach, donde privan la observación, la inducción, las proposiciones descriptivas, la verificación o falsación. Michael Polanyi (1958) ${ }^{24}$ le llama a ello pasión heurística y pasión persuasiva.

\section{La retórica y el discurso administrativo: la pasión persuasiva}

En diversos textos se presenta un proceso retórico de argumentación racional donde se van a dar las 2 pasiones: por persuadirnos ${ }^{25}$ y la pasión heurística ${ }^{26}$. Es interesante el caso de 2 teóricos de la administración: Koontz y Reyes Ponce. Los 2 tratarán de convencer a un auditorio de tener el mejor modelo administrativo que los llevará al logro de sus objetivos.

\footnotetext{
24 Al respecto se sugiere revisar de Polanyi el capítulo 6, «Intellectual Passions», de su texto Personal Knowledge, pp. 132- 2001. En particular el subtema 3 del capítulo 6: «Heuristic passion» (Polanyi, 1958: 142).

${ }^{25}$ La justificación de creencias no solo se hace por el uso de un método universal, seguro, único, algorítmico y concluyente, ya como demostración lógica o como comprobación empírica. La justificación racional de creencias (y acciones) con base en evidencia empírica es una más. Pero parece más importante la justificación de creencias por persuasión, retórica, basadas en argumentación. La argumentación refuerza creencias, cambia creencias, de cerca con el diálogo, la dialéctica, la crítica, la evaluación, lo que debe ser. Define qué conocimiento debe reproducirse o abandonarse, con argumentos, dando razones y pidiendo razones. La persuasión remite a ese proceso retórico, argumentativo de modificar creencias, reforzar creencias y definir cuáles son verdaderas y cuáles no. Por ello la persuasión pertenece a la pragmática: constituye creencias y acciones, y ello nos lleva a un nuevo contexto de justificación de creencias.

26 Imre Lakatos (1975: 244) habla de heurística negativa y positiva en cada programa de investigación científica. Larry Laudan (1986: 131) nos habla de la heurística en las tradiciones de investigación. Polanyi (1958: 142) nos habla de la heurística del conocimiento producido por los científicos. Los programas de investigación, las tradiciones de investigación, como los científicos, pueden ser evaluados por su capacidad heurística. El progreso de los programas y las tradiciones de investigación científica en buena medida se debe a su potencialidad heurística. Coinciden Lakatos, Laudan y Polanyi en considerar la heurística como ese potencial de investigación para guiar el descubrimiento de nuevos hechos, plantear nuevos problemas, formular soluciones innovadoras, formular nuevas hipótesis, modelos, diferente a buscar la adecuación empírica. Heurística refiere para ellos —y en este trabajo - al medio eficaz para descubrir, crear, innovar, formular, en este caso nuevos modelos. En el discurso administrativo se puede ver el potencial heurístico, ahora en lo que resalto, en la producción de modelos en el discurso administrativo. Que la heurística, entendida así, nos lleva a un nuevo contexto de descubrimiento.
} 
En este apartado resalto, de la retórica, la pasión persuasiva que se caracteriza por la argumentación, la crítica, la evaluación, la elaboración de juicios de valor, al considerar conceptos, modelos o constructos, proposiciones, tesis, de otros autores.

Jorge Ríos desde una pasión ṕersuasiva ubica a Koontz en un modelo teórico-descriptivo. Ahora sabemos que en ciencias sociales y humanidades describir también es prescribir. Describir cómo es la libertad, prescribe cómo debe ser la libertad; al describir Koontz un modelo de 5 elementos, prescribe su modelo administrativo.

Desde luego, Koontz and Weihrich, 1998 es el que llama más mi atención, por ser muy directo respecto a las bondades del modelo que nos ofrece, de 5 elementos. Koontz enfrenta otros modelos como el de 4 elementos de Terry (planeación, organización, ejecución y control); el de Stoner et al. (1995) (planeación, organización, dirección y control), el de Daft y Marcic (2007) (planeación, organización, liderazgo y control). Pero quizá lo interesante de él es que señala un desorden en el discurso administrativo. Hay una «jungla semántica», estamos frente a la selva de la teoría administrativa. Estamos frente a lo salvaje que hay que civilizar: el desorden que hay que meter en orden. En su libro de 796 páginas nos intentará mostrar cómo mete al orden lo diverso. Es más, llega a hablar de «evolución del pensamiento administrativo y de los patrones de análisis administrativo» (Koontz and Weihrich, 1998: 16), donde al final de esta semblanza histórica se presenta su modelo de 5 funciones. Así, podemos pasar por un proceso histórico teórico: administración científica (Frederick W. Taylor, Henry L. Gantt, Frank Gilbreth); administración operacional (Henri Fayol); ciencias de la conducta (Walter Scott, Max Weber, Vilfredo Pareto, Elton Mayo); teoría de sistemas (Chester Bernard); pensamiento administrativo moderno (Peter Drucker, Edwards Deming, Wiliam Ouchi, Robert Walterman). ¿Cómo lograr la unidad de lo diverso? Al mostrar cómo domestica la diferencia, donde se puede ver no solo la pasión por la persuasión, sino también la pasión heurística: mostrando su constructo, su modelo, el cual repetirá al inicio de cada función. En ese constructo producto de la pasión heurística construirá un modelo que, pese a su interés por lo descriptivo y por lo predictivo, me parece que se ubica mejor en un plano prescriptivo. Koontz tuvo la poca fortuna de caer en la necesidad de querer cumplir con la exigencia cientificista moderna, positivista, por desconocimiento de la obra de Austin, de Searle, de Toulmin, de Perelman, de la retórica, de la semiótica, de la pragmática.

Es sugestivo el proceso argumentativo de Koontz al inicio de su obra. El enfrentamiento y la recuperación conceptual de diversos enfoques administrativos son interesantes. En un cuadro resumen nos muestra las aportaciones y las limitaciones de diversos enfoques, asistimos a una controversia, a una discusión crítica de los diversos puntos de vista. Koontz enfrenta a los diversos enfoques: el empírico o de casos, el de los papeles administrativos, el de contingencias o situacional, el matemático, o de la «ciencia de la administración», el de la teoría de las decisiones, el de reingeniería, el de sistemas, el de sistemas sociotécnicos, el de sistemas sociales cooperativos, el de comportamiento grupal, el de comportamiento interpersonal, el de las 7-S de McKisey, el de la administración de la calidad total, el de proceso administrativo u operacional. Koontz los caracteriza, señala sus contribuciones, pero también sus limitaciones. Pero con ello, como señalé, muestra lo diverso, que requiere alguna unidad. En la evolución, donde se presentan las diferencias, reclama una unidad que ordene. Y así, al final del capítulo nos presenta su modelo que dará unidad a lo diverso, la síntesis hegeliana. Para darle más certidumbre, nos dice que está haciendo ciencia, que trabaja con enunciados descriptivos, predictivos, no normativos o prescriptivos (Koontz and Weihrich, 1998: 15).

$\mathrm{Su}$ capítulo uno es un capítulo donde se puede ver la pasión persuasiva, justificadora, argumentativa, con fuertes discusiones, con teóricos, con teorías, con enfoques, para llegar a su propuesta finalmente. Al inicio, cuando define lo que es la administración, nos pone de hecho en 
los enunciados performativos: «la administración es el proceso de diseñar y mantener un entorno, en el que, trabajando en grupos, los individuos cumplan eficientemente objetivos específicos». Los administradores deben cumplir las funciones administrativas de planeación, organización, integración de personal, dirección y control. Sin olvidar que la intención de todo administrador es generar un superávit. La administración persigue la productividad, lo que implica la eficacia y la eficiencia. El convencimiento de su modelo de 5 funciones pretende hacerlo universal, convencer a un auditorio universal, sobre los otros modelos con diferentes funciones, como el de 4 (Terry, Stoner, Hampton) o como el de 6 elementos (Reyes Ponce).

Reyes Ponce es otro autor que podemos ubicar en el campo de la retórica de la investigación científica, en este caso desde la pasión persuasiva. En sus textos podemos encontrar un proceso de argumentación y de proposiciones no demostrativas alejados del método científico. Como Jorge Ríos señala, su modelo es prescriptivo, es decir, utiliza proposiciones prescriptivas al formular su modelo de 6 elementos que llama proceso administrativo: 3 elementos ubicados en la fase mecánica (previsión, planeación y organización) y 3 elementos ubicados en la fase dinámica (integración, dirección y control). En una interesante discusión retórica, Reyes toma las fases de Urwick (Reyes Ponce, 2004: 26). Y uno de los motivos de usar oraciones prescriptivas se debe a que no quiere caer en el error de Terry y aun de Koontz, que no distinguen entre previsión (lo que puede hacerse) y planeación (lo que se va hacer de hecho), pero aún más, forzar a la mente, de entre diversos cursos alternativos, a buscar el mejor, así partimos de «algo que debe hacerse», lo mejor, nos dice Reyes Ponce (2004: 24). Y ello no se plantea con enunciados descriptivos.

El capítulo segundo de Reyes Ponce (2004: 21-36), rico en retórica, donde se debate, critica, desarrolla juicios de valor, reflexiona, argumenta, trata de persuadir, con el objetivo de convencer a un auditorio universal. En este capítulo el debate se desarrolla por la presentación de criterios de división de los elementos de la Administración. Reyes lo hace «haciendo notar los problemas que se presentan en cada uno de ellos». Pero finalmente, «recogiendo lo más útil, a nuestro juicio, de las diversas clasificaciones de los elementos», formulará la suya, la que debe ser, la mejor. Señala a quien le debe en buena medida su propuesta: a Terry y Koontz y O’Donnell. Después de un debate, elimina lo que considera inútil de los otros modelos.

El modelo de proceso administrativo de la American Management Association que presenta una propuesta de 3 elementos (planeación, organización y supervisión) es muy amplia, no añade mucho al modelo de Urwick. La organización, como la presenta, no se puede ubicar con claridad en la fase mecánica o dinámica. La división de 4 elementos de Terry (planeación, organización, ejecución y control), pese a que es sencilla, está muy generalizada y distingue las 2 fases: de la mecánica, planeación y organización, y de la dinámica, dirección o ejecución y control, aunque adolece de 2 limitaciones: no distingue previsión de planeación, entre lo que puede hacerse y lo que va hacerse; y segundo, limita la posibilidad para la creatividad, para encontrar entre los diversos cursos alternativos, el mejor. Así, los planes no deben entenderse como lo primero que se me ocurre, o como lo que siempre hemos venido haciendo, limitando nuestra creatividad. Retoma el argumento de Drucker sobre la falacia o sofisma del camino único; los planes de los que partimos no son los mejores ni los únicos: pueden existir otros más eficientes.

Al debatir con el modelo de Fayol de 5 elementos en la administración (prever, organizar, mandar, coordinar y controlar) señala Reyes Ponce que comete un error al poner como «elemento» lo que es la esencia de todos, y en todos se da: la «coordinación». Respecto a Harold Koontz, pese a afirmar que se basa en la división de 5 elementos (planeación, organización, integración, dirección y control), no considera un elemento importante la previsión, que debe darse antes de la planeación, considerando la crítica arriba señalada a Terry. El modelo de Ernest Dale, compuesto de 7 elementos aunque presentados en 6 , en el sexto mete 2: 1) planeación y previsión, 
2) organización, 3) integración, 4) dirección, 5) control y 6) innovación y representación. Respecto a estos últimos, le parece a Reyes que la innovación se fija en los planes, se propone al fijar diversos tipos de planes, por lo que no es necesario separarlo como elemento. Y la representación es un fenómeno jurídico que se identifica con el mandato, ya que el jefe superior es el mandante y el jefe inferior es el mandatario. Por ello está implícito en el elemento de la dirección, en la delegación, por lo que no es necesario considerarlo como elemento. La discusión la continúa Reyes. Quizá como ejemplos quede lo anterior, donde muestro como el discurso administrativo de Reyes es un discurso retórico donde se da la pasión por la persuasión, por la argumentación racional, por la discusión, por la crítica, por la evaluación. Desde luego, la argumentación, la discusión retórica, se da a lo largo del texto. Como Koontz, el objetivo de su retórica es persuadir, convencer a un auditorio universal de su modelo de 6 elementos.

\section{La pasión por la heurística en el discurso administrativo}

Una parte interesante de la retórica es la pasión heurística ${ }^{27}$, creativa, en el proceso argumentativo se muestran constructos deseables, modelos, patrones, regularidades, viables, verosímiles, posibles, así como hipótesis. El origen de lo anterior no es la experiencia, como consideraba el positivismo: viene de la misma tradición discursiva como de otra tradición discursiva. Gadamer, Popper, Kuhn, Lakatos y Laudan, entre otros, ya lo habían dejado ver cuando hablaban de la pertenencia a una tradición con sus prejuicios, a una cultura, a un paradigma, a un programa de investigación o a una tradición de investigación; independientemente de que se hallen falsas algunas de sus hipótesis, lo que importa es su capacidad heurística, por su potencialidad en la formulación de nuevos constructos, modelos, conceptos, hipótesis. En la producción de modelos o constructos no se parte de cero, siempre estamos en alguna tradición. Los autores desde la tradición ${ }^{28}$ en la que se encuentren (desde los conflictos internos a la tradición), o que mantienen con otra tradición (los conflictos externos que se mantenga con otras tradiciones), surgen los constructos, hipótesis o teorías en la búsqueda de solución de confrontaciones retóricas.

En Koontz es claro cuando propone solucionar la jungla de las teorías administrativas ${ }^{29}$.

La riqueza de constructos es importante en el discurso administrativo. Mostraré un poco de esta creatividad que se da en administración, esto es, la pasión heurística.

Mary Parker Follet hizo interesantes propuestas. Una de ellas fue su modelo de «control holístico», y un concepto que le pertenece es el modelo de mando, en cual divide en 3 tipos de mando: por posición, por personalidad y, el que propone ella, el funcional.

\footnotetext{
27 Para Lakatos (1983: 69), un programa de investigación progresivo es el que tiene una heurística positiva fuerte, «establece un programa que enuncia una secuencia de modelos crecientemente complicados simuladores de la realidad: la atención del científico se concentra en la construcción según las instrucciones establecidas en la parte positiva de su programa». Aunque Lakatos habla de modelos descriptivos, yo hablo de modelos prescriptivos, que solo se aplican al campo humano.

28 Puede ser útil la definición de tradición de MacIntyre (1988): «Una tradición es un argumento que se extiende a través del tiempo, en el cual algunos acuerdos fundamentales se definen y redefinen en términos de 2 tipos de conflictos: aquellos con críticos o enemigos externos a la tradición que rechazan todo o parte de los elementos claves de esos acuerdos fundamentales, y aquellos al interior de la tradición en los que se desarrollan debates interpretativos a través de los cuales el significado y la racionalidad de los acuerdos fundamentales se especifican y gracias a los cuales la tradición se constituye».

29 Con este concepto refiere Koontz a la variedad de enfoques administrativos, la cantidad considerable de investigaciones diferentes, el gran número de puntos de vista divergentes. Todo ello creando confusión, la Babel administrativa, pero que Koontz propone solucionar con su modelo de 5 elementos, donde cualquier concepto, teoría, constructo hallará un lugar en cualquiera de sus 5 categorías.
} 
Follet (1949) enfrenta una discusión en varios frentes, contra el argumento de que «los jefes nacen, no se hacen» o que «el mando es una capacidad que no puede adquirirse». Ella nos dice: «Tengo la esperanza de que ustedes no permitan que nadie los persuada de que [el jefe] no puede hacerse» (Follett, 2000: 289). Además de que se puede aprender el mando, las personas pueden pasar de una posición subordinada a una de mando. Es una situación democrática.

En dicho modelo consideraba diversos factores: los individuos, los grupos y el ambiente, pero en particular las formas de mando. En el capítulo «Los elementos esenciales del mando» (Follett, 2000) establece una discusión contra una forma de mando, pero a la vez propone otra. En esa pasión retórica, en su argumentación, se ubica en la pasión heurística al construir modelos de mando que nos recuerdan el autoritario: el individualista y el «funcional-participativo». En este segundo modelo lo relacionan con el concepto de empowerment. El primer modelo de mando se caracteriza por ser el autoritario, violento, belicoso, agresivo, imperioso, dominante, que ordena, y fue dominante en las empresas. En este modelo el hombre de negocios tradicional se siente bien dando órdenes. Le gusta establecer leyes, normas, políticas, un modelo de gobierno monárquico, no demócrata, menos republicano, imponiéndoles. Con dichas proposiciones, Follet va construyendo un modelo que también es prescriptivo, una identidad, un tipo ideal, al estilo de Weber. Modelo que es retórico, cuya crítica posibilita evitar que se repita, evitar que se sigan construyendo identidades humanas de hombres y mujeres de negocios semejantes.

Otro de sus modelos es el de personalidad, y por cuestiones de espacio mencionaré las características que propone del modelo de mando por personalidad, superior al anterior. Las cualidades personales que debe tener son: «tenacidad, franqueza, trato correcto con todos, constancia de propósito, profundidad de convicción, control de temperamento, firmeza en periodos tempestuosos, capacidad de hacer frente a las emergencias, desarrollar las posibilidades latentes de los demás y, sobre todo, fuerza de ejemplo» ${ }^{30}$.

El mando funcional, distinto, en particular al autoritario, sin dejar a un lado el de personalidad, trabaja en grupo: organiza la experiencia del grupo para obtener toda la energía del mismo. El jefe forma el equipo. La capacidad de mando se mide por su capacidad para organizar todas las fuerzas existentes en una empresa y hacerlas servir a un fin común (Follett, 2000: 283). Crean fuerza de grupo, más allá de la fuerza personal. El gran jefe crea y dirige la fuerza. El jefe deja de ver la interrelación de todas las piezas. Las ideas u sugestiones no vienen fundamentalmente de arriba, sino de abajo, el jefe consiente dichas participaciones y las alienta. El trabajador no cumple su responsabilidad solamente obedeciendo, en este modelo. Es mala la obediencia pasiva. Una orden equivocada debe poder cuestionarla con argumentos, y el jefe de aceptar. El hombre que dice sí a todo no es el que se debe formar en una empresa, se debe formar un hombre inteligente. Se debe fomentar, crear la obediencia activa, por parte del mando. Debe dejar claro el jefe que él y sus seguidores, ambos, deben ser seguidores del jefe invisible: el propósito común. Deben quedar persuadidos del propósito común. Es tarea del jefe. El propósito común es el jefe de todos y responsabilidad de todos. El jefe invisible debe ser la fuerza que mueva a todos. Con ello, el jefe fomentará la obediencia activa.

La pasión heurística de Koontz et al. (2012: 30) lo lleva a crear modelos diversos. Al cuestionar y argumentar contra otros modelos de funciones de la administración y de tratar de ofrecer una solución a la jungla semántica administrativa, crea un modelo, su modelo de 5 elementos.

\footnotetext{
${ }^{30}$ En su texto Los elementos esenciales del mando Follett (2000), con su argumentación, potencializa nuevas hipótesis respecto a los jefes, al mando, a la dirección, a los gerentes.
} 
Las funciones gerenciales proporcionan una estructura útil para organizar conocimiento administrativo. Todas las nuevas ideas, los nuevos descubrimientos de investigación o técnicas pueden colocarse con facilidad en las clasificaciones de planear, organizar, integrar personal, dirigir o controlar.

Este es el modelo que propone Koontz ${ }^{31}$, con el que va a solucionar la Babel, confusión, caos, administrativo. Planear: elegir misiones y objetivos, así como las acciones para alcanzarlas, lo que requiere decidir. Organizar: establecer una estructura intencional de funciones que las personas desempeñen en una organización. Integrar el personal: cubrir y mantener cubiertos los puestos en la estructura organizacional. Dirigir: influir en las personas para que contribuyan a las metas organizacionales y de grupo. Controlar: medir y corregir el desempeño individual y organizacional para asegurar que los hechos se conforman a los planes. Dicho modelo retórico está hecho con proposiciones no demostrables sino performativas (Austin), fuera de la posibilidad de explicación o predicción y cercana a la prescripción.

La pasión heurística en administración, y con ello la innovación de artefactos conceptuales, ha sido basta. Fayol nos habla de su modelo de principios administrativos. Peter Drucker nos habla de su modelo APO (administración por objetivos), preocupados por los CEO. Chester Bernard nos propone su modelo de las funciones o tareas del gerente o ejecutivo. Henry Mintzberg, uno de los críticos del modelo de Koontz — señala que los ejecutivos realmente no realizan las funciones gerenciales clásicas: planear, organizar, comandar, coordinar y controlar-, propone su modelo de 10 funciones que sí realizan los gerentes. William Deming nos habla de su modelo de control de la calidad. McKinsey propone su modelo de «las $7 \mathrm{~S}$ »: estrategia, estructura, sistemas, estilo, personal, valores compartidos y habilidades. Peter Senge (Senge, 2014) nos muestra su modelo de las 5 disciplinas: pensamiento sistémico, dominio personal, modelos mentales, construcción de una visión compartida, aprendizaje en equipo. Michael Porter propone su modelo de 4 factores que ayudan al bienestar de una nación (más allá de la teoría de la ventaja competitiva; Koontz et al., 2012: 85): las condiciones de factor o recursos de la nación; condiciones de demanda; proveedores, estrategia y estructura, y la rivalidad de los competidores.

Por cuestiones de espacio, la lista la dejo en esos importantes nombres y modelos. Ellos pueden mostrar la potencialidad de la pasión heurística del discurso administrativo.

\section{Conclusiones}

1. La tesis que he propuesto es que numerosos textos e investigaciones en administración parecen moverse en el campo de la retórica, alejados de las demostraciones empíricas. Desde los textos introductorios como los de Harold Koonz, Stoner, Hampton, Chiavenato, Reyes Ponce, Isaac Valdivia, como de los textos de Henry Fayol, Mary Parker Follet, Peter Drucker, Chester Bernard, Henry Mintzberg, William Deming, Juran, Peter Senge, Michael Porter, entre otros. Muestro algunos casos.

2. La metodología demostrativa entendía al conocimiento racional como conjunto de proposiciones demostrables por evidencias empíricas. Ella dominó hasta el siglo pasado. Frege, Russel, Carnap, Nuerath (Perelman y Olbrechts, 1989), en general, el positivismo lógico, estaban convencidos de esta idea. Su retórica se enfocó a subrayar la verificación, la inducción, el contexto

\footnotetext{
${ }^{31}$ El texto de Koontz et al. (2012) puedo decir que está lleno de esta pasión heurística. Pero sugiero ver el capítulo 1 (pp. 1-38), donde nos habla de teorías administrativas, de autores, de enfoques administrativos, de la jungla semántica en administración.
} 
de descubrimiento, el contexto de justificación, la evidencia empírica, el método científico, la atención a la semántica y la sintaxis, desconociendo la pragmática, el giro pragmático, su crítica a la metafísica. Más allá de esa racionalidad, con Perelman, la que ahora se propone recuperar es la racionalidad adecuada al análisis y evaluación de proposiciones no demostrativas, a los argumentos, a las controversias sobre juicios de valor, en general a las ciencias sociales y humanidades, y ahora a buena cantidad de proposiciones fundamentales de la administración. El trabajo se ubica en la racionalidad práctica aristotélica, reivindicando las proposiciones de estas ciencias sociales y humanidades con validez cognoscitiva. Se propuso ver a la retórica como teoría de la argumentación, con proposiciones no demostrables, pero con capacidad heurística como persuasiva. Se propuso ver a la retórica como necesaria para entender qué pasa con la justicia, la democracia, los modelos de desarrollo, la bondad, el papel del Estado, del mercado; pero también con el proceso administrativo, las funciones de la administración, el hombre administrativo, la racionalidad económica, la racionalidad instrumental, la misión, las metas, las políticas, las normas, los perfiles de puesto, la centralización o descentralización del poder, la autoridad, el poder, modelos de comunicación (autoritarios o democráticos).

3. Una postura a la que me sumé y en la que puedo ubicar este trabajo es la denominada retórica de la investigación científica, con Polanyi, Kuhn, Fuller, Nelson, Kitcher, Toulmin y Perelman. En esta, la investigación científica se entiende como un proceso dialógico que se desarrolla en comunidades científicas. En ella, el diálogo, la argumentación retórica desempeña un papel esencial para la defensa y el reconocimiento y justificación de hipótesis y teorías (fuerza persuasiva y contexto de justificación), así como para su crítica y sustitución por otras más razonables, formulando modelos, constructos alternativos (fuerza heurística y contexto de descubrimiento). La racionalidad es un proceso comunicativo entre personas de cierta comunidad que comparten presupuestos, debaten críticamente diversas tesis y buscan hacer consensos racionalmente en aspectos esenciales de la controversia. En administración, las controversias respecto al proceso administrativo son interesantes, donde se busca el convencimiento de un auditorio, como la innovación heurística.

4. Desde la retórica se destaca en el discurso administrativo la pasión persuasiva y heurística: la búsqueda de la adhesión de un auditorio a ciertas creencias, teorías o modelos y a la creación de estos. En diversos textos se mostró el proceso retórico de argumentación racional donde se presentan las 2 pasiones: por persuadirnos y la heurística. Es interesante el caso de 2 teóricos de la administración: Koontz y Reyes Ponce. Los 2 tratarán de convencer a un auditorio de tener el mejor modelo administrativo que los llevará al logro de sus objetivos. En este apartado resalté, de la retórica, la pasión persuasiva que se caracteriza por la argumentación, la crítica, la evaluación, la elaboración de juicios de valor, al considerar conceptos, modelos o constructos, proposiciones, tesis, de otros autores, buscando su adhesión, convencimiento. Koontz en su pasión por la persuasión tratará de meter en orden a la «jungla semántica», caótica de la administración, con su modelo de 5 elementos. Por su parte, Reyes Ponce enfrentará a los modelos de proceso administrativo que no consideran la previsión, resaltando lo importante de buscar lo mejor, lo que debe hacerse, proponiendo un modelo de proceso con corte prescriptivo. Ambos buscarán persuadir a un auditorio universal, sin lograrlo, pues enriquecen la jungla semántica de las funciones y procesos administrativos.

5. Una parte interesante de la retórica es la pasión heurística, creativa y de innovación. En el proceso argumentativo se innovan, se muestran constructos deseables, modelos, patrones, regularidades, viables, verosímiles, posibles, así como hipótesis. El origen de lo anterior no es la experiencia como consideraba el positivismo, viene de la confrontación y de los conflictos internos a la misma tradición discursiva, a la que pertenece el autor, como con otra 
tradición discursiva. Mostré 2 ejemplos heurísticos: Koontz al intentar meter al orden a la jungla semántica de la administración produce su modelo de funciones de la administración en 5 pasos: planeación, organización, integración, dirección y control. Modelo que, en palabras de Koontz, puede dar cabida a los diversos conceptos administrativos existentes, como los que pudieran surgir, dándoles orden. Por otra parte, Mary Parker Follet, en su controversia contra el modelo de mando autoritario, violento, belicoso, agresivo, imperioso, dominante, que ordena, propone que hay al menos 3 modelos de mando: el autoritario, el personal y el funcional. En su propuesta trata de persuadir del modelo funcional, sin demérito del personal y en franca crítica al modelo autoritario.

6. Lo anterior tiene, al menos, 2 consecuencias en el mundo académico y en la práctica administrativa. El mundo académico no debiera considerar el discurso administrativo tan solo de acuerdo al modelo positivista.

7. Lo anterior tiene consecuencias tanto en el mundo académico como en el de la práctica administrativa. Primera consecuencia: el mundo académico ya no debiera considerar al discurso administrativo solo de acuerdo al modelo positivista. Más allá de las proposiciones demostrativas, constatativas, como únicas formas de conocimiento, ahora desde la pragmática se mostró cómo se hacen cosas con palabras (Austin). Se abre el mundo del lenguaje y su función pragmática, en su perspectiva retórica, argumentativa. Ahora, en buena medida, los textos administrativos deberán ser vistos como textos retóricos, más que demostrativos. Al cumplir con 2 funciones - persuasiva y heurística - persuaden y constituyen ciertos conocimientos, creencias - distante de la idea ingenua empirista de que el conocimiento viene de la experiencia, de la observación: el conocimiento viene de la retórica, de la persuasión y argumentación, en este caso, del discurso administrativo-. Segunda consecuencia: se pude ver que las palabras también causan acciones, forman patrones de acción; con Searle, decimos que construyen la realidad social. El discurso administrativo construye organizaciones productivas, no de forma necesaria, siempre contingencial. Respecto a la práctica administrativa ahora, desde la perspectiva pragmática, el discurso administrativo permite entender lo que sucede en las organizaciones sociales. Dentro de ellas se pide y se dan razones, y en un regreso a la idea aristotélica de considerar al hombre como racional podemos ver que en buena medida que las personas se mueven por razones, por argumentos, por palabras. Palabras que forman argumentos, modelos deseables, lo que debe ser, políticas, misiones, objetivos, que por argumento estratégico, de autoridad o por consenso, constituyen creencias y mueven las acciones humanas.

\section{Referencias}

Arendt, H. (2007). La condición humana. México: Paidós.

Austin, J. (1955). Cómo hacer cosas con palabras. Consultado 12 de febrero de 2013. Disponible en: http://www. philosophia.cl/biblioteca/austin/C\%F3mo\%20hacer\%20cosas\%20con\%20palabras.pdf

Aristóteles. (2005). El arte de la retórica. Buenos Aires: Eudeba.

Bárcenas R. (2002). Contexto de Descubrimiento y Contexto de Justificación: Un problema Filosófico en la Investigación Científica. Redalyc, mayo-agosto, Vol. 12, (2): 48-57. Disponible en: http://www.redalyc.org/articulo. oa?id=41600206. También en: Revista Acta Universitaria. Multidisciplinary Scientific Journal. Vol. 12 No. 2 MayoAgosto 2002. Disponible en http://www.actauniversitaria.ugto.mx/index.php/acta/article/view/282/260

Barthes, Roland. (1977). Introducción al análisis estructural de los relatos. Buenos Aires: Centro Editor América Latina. Berger, P. y Luckmann, T. (2008). La construcción social de la realidad. Buenos Aires: Amorrortu.

Berlin, I. (1958). Dos conceptos de libertad. Oxford: Clarendon Press.

Bruner, J. (1998). Realidad mental y mundos posibles. Barcelona: Gedisa. 
Cruz Soto, L. A. (2010). El concepto de autoridad en el pensamiento de Aristóteles y su relación con el concepto de autoridad en el comportamiento administrativo. Contaduría y Administración, 231, 53-78.

Czarniawska, B. (1997). Narrating the organization. Dramas of Institutional Identity. The University of Chicago Press.

Daft, R. y Marcic, D. (2007). Introducción a la administración (4. a ed). México: Thomson.

Follett, M. P. (1949). Freedom and Co-ordination. Londres: Management Publications.

Follett, M. P. (2000). Los elementos esenciales del mando. Tomado de la compilación de Merrill del libro Clásicos en administración, México, Limusa.

Galicia Osuna D. (2013). «Filosofía administrativa: La construcción de organizaciones desde constructos o artefactos sociales». Ponencia, XVIII Congreso Internacional de Contaduría, Administración e Informática. Universidad Nacional Autónoma de México.

Giddens, A. (1993). Las nuevas reglas del método sociológico. Buenos Aires: Amorrortu editores.

Habermas, J. (1997). El giro pragmático de Rorty. Isegoría, 17, 5-36.

Hempel Carl (1950). Problemas y cambios en el criterio empirista de significado. En: Ayer A.J. (comp.). El positivismo lógico. México: Fondo de Cultura Económica; 1986.

Koontz, H. y Weihrich, H. (1998). Administración una perspectiva global (11. a edición). México: MacGrawHill.

Koontz, H., Weihrich, H. y Canice, M. (2012). Administración. Una perspectiva global y empresarial (14. ${ }^{a}$ edición). México: McGrawHill.

MacIntyre, A. (1988). Whose Justice? Wich Rationality? Notre Dame: University Notr Dam Pres [Traducción al castellano: Justicia y Racionalidad. Barcelona. 1994.].

Morgan, G. (1991). Imágenes de la organización. México: Alfaomega.

Lakatos, I. (1975). La falsación y la metodología de los programas de investigación científica. En I. Lakatos y A. Musgrave (Eds.), La crítica y el desarrollo del conocimiento científico. Barcelona: Grijalbo.

Lakatos, I. (1983). La metodología de los programas de investigación científica. Madrid: Alianza Editorial.

Laudan, L. (1986). El progreso y sus problemas. Madrid: Encuentro.

Perelman, C. H. y Olbrechts, T. (1989). Tratado de la argumentación. La nueva retórica. Madrid: Biblioteca Románica Hispánica.

Polanyi, M. (1958). Personal Knowledge. Londres: Routdledge and Kegan Paul.

Popper, K. (1980). La lógica de la investigación científica. Madrid: Tecnos.

Reyes Ponce, A. (2004). Administración moderna. México: Limusa.

Ríos Szalay, J. (1997). Mitos sobre el proceso administrativo: el modelo teórico-descriptivo vis-a-vis el modelo técnicoprescriptivo. Contaduría y Administración, 185, 49-61.

Santibañez, C. (2010). Retórica, dialéctica o pragmática: a 50 años de los usos de la argumentación de Stephen Toulmin. Revistas Científicas Complutenses. Círculo de lingüística aplicada a la comunicación, 42, 91-125.

Searle, J. (1997). La construcción de la realidad social. México: Paidós Básica.

Senge P. (2014). La quinta disciplina. Consultado 18 de febrero de 2014. Disponible en: http://gerenciaestrategica. pbworks.com/w/file/fetch/55691078/LA\%2520QUINTA\%2520DISCIPLINA\%2520-\%2520PETER\%2520SENGE. pdf

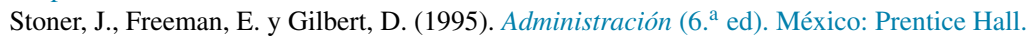

Toulmin, Stephen. (2007). Los usos de la argumentación. Barcelona: Península.

Van Dijk, T. (2008). El discurso como interacción. Estudios sobre el discurso II. Una introducción multidisciplinaria. Barcelona: Gedisa.

Velasco A. (coordinador) (2000). El concepto de heurística en las ciencias sociales. México: Siglo XXI, UNAM.

Velasco A. (2006). Retórica y racionalidad de las tradiciones políticas y científicas. Consultado 11 de agosto de 2013. Disponible en: http://fenix.cichcu.unam.mx/libroe_2006/0004062/20_c16.pdf

Wolin, S. (1996). Democracia, Diferencia y Re-conocimiento. pp. 133-152. Argentina: Ágora, Cuadernos de Estudios Políticos No. 4. 